\title{
Responses to gastric distension in functional dyspepsia
}

\author{
G A M Salet, M Samsom, J M M Roelofs, G P van Berge Henegouwen, A J P M Smout, \\ L M A Akkermans
}

practice. ${ }^{1}$ Patients with functional dyspepsia present with a diversity of symptoms, associated with the upper gastrointestinal tract, which include inability to finish a normal meal, feeling of fullness, distension, nausea, vomiting, epigastric pain, and bloating. Most of these symptoms occur postprandially.

Scintigraphic studies have shown a delay in gastric emptying in $29-59 \%$ of dyspeptic patients. ${ }^{23}$ In about $60 \%$ of patients, ${ }^{45}$ antroduodenal manometry showed postprandial antral hypomotility and disorganised patterns of intestinal motility, ${ }^{6}$ and a reduced number of activity fronts with an antral component in the fasting state. ${ }^{4}$ These motility disorders are not a satisfactory explanation for the symptoms in all patients, since in a substantial subgroup of dyspeptic patients no motor abnormality can be found and moreover symptoms do not correlate well with manometric findings. ${ }^{78}$ Therefore other pathophysiological mechanisms may be involved in functional dyspepsia. For instance, it has been shown that the threshold for pain or discomfort in response to gastric distension, in the fasted state, is lower in patients with functional dyspepsia than in healthy volunteers. ${ }^{9-11}$ Troncon and coworkers ${ }^{11}$ inflated a plastic bag in the proximal stomach and measured pressures before and after a meal, without the use of a barostat. They found that, in contrast with controls, patients with functional dyspepia showed no reduction in mean pressure in an intragastric balloon during and after the meal. However, it is not yet certain whether the symptoms are caused by hypersensitivity of the proximal stomach or by an alteration of the proximal stomach motor function. The aim of this study was to investigate adaptation of the proximal stomach to distension and accommodation in response to a liquid meal in functional dyspepsia. Furthermore, relations between dyspeptic symptoms and accommodation and distension in these patients were assessed.

\section{Materials and methods}

HEALTHY VOLUNTEERS AND PATIENTS

Twelve healthy volunteers (five men and seven women: mean age 36 years, range 26-62 years), without gastrointestinal symptoms, and 12 patients with dysmotility-like dyspepsia ${ }^{12}$ (five men and seven women: mean age 37 years, range 22-62 years) participated in the study after giving written informed consent. The protocol of the study had been approved by the medical ethical committee of the Utrecht University Hospital. Patients were selected by their answers to a questionnaire

\begin{abstract}
to mechanical distension. Their visceral
percest with the bal
\end{abstract}

Functional dyspepsia, also known as non-ulcer or essential dyspepsia, is diagnosed in nearly one quarter of all patients with dyspeptic symptoms seen in gastroenterological
Keywords: dyspepsia; gastric distension; gastric

\author{
Accepted for publication \\ 18 December 1997 \\ Surgery, Gastrointestinal \\ University Hospital, PO Box \\ 85500-3508 GA, Utrecht, \\ Surgery, Utrecht \\ Department of \\ Henegouwen \\ Correspondence to: \\ Professor L M A Akkermans, \\ Department of Experimental \\ Motility Unit, Utrecht \\ The Netherlands.
}

University Hospital, dyspepsia show slightly higher compliance 


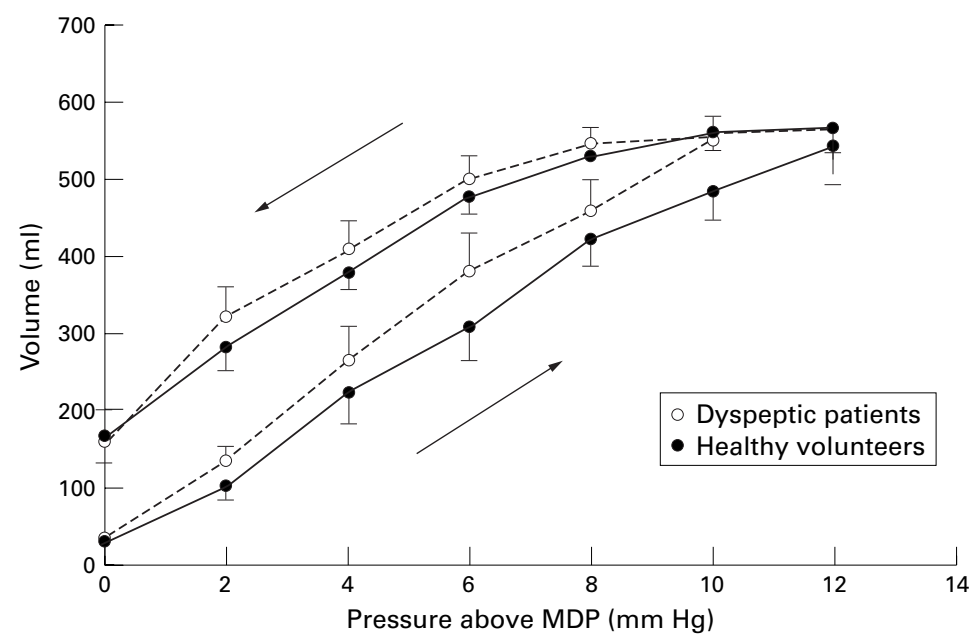

Figure 1 Mean volume-pressure curve in the dyspeptic patients and healthy volunteers. The inflation (ascending part of the pressure-volume) curve showed a significantly steeper slope $(p<0.05)$ in the dyspeptic patients than in the controls, indicating a higher compliance in the dyspeptic patients. The descending part of the pressure-volume curve (deflation) showed a delay in the return of the gastric volume toward the values at minimal distending pressure (MDP) (hysteresis).

( 0 , no symptoms; 4, very severe symptoms; maximum score 20). The presence of at least two of five symptoms was required: (1) inability to finish a normal meal; (2) feeling of postprandial fullness and/or upper abdominal distension; (3) nausea and/or vomiting associated with eating; (4) feeling of slow digestion; (5) epigastric pain. These symptoms had to be chronic - that is, to have been present for more than three months-and to occur primarily postprandially and frequently-that is, on average more than three times a week. Physical examination, oesophagogastroduodenal endoscopy, and upper abdominal ultrasonography, all performed within the preceding year, had to show no anatomical abnormalities. The patients had no history of gastrointestinal surgery (other than appendectomy, inguinal and crural hernia repair, haemorrhoidectomy).

\section{ELECTRONIC BAROSTAT}

The barostat measures the volume of air pumped into a polyethylene bag, maintained at a constant preselected mean pressure level by an electronic feedback mechanism. ${ }^{13}$

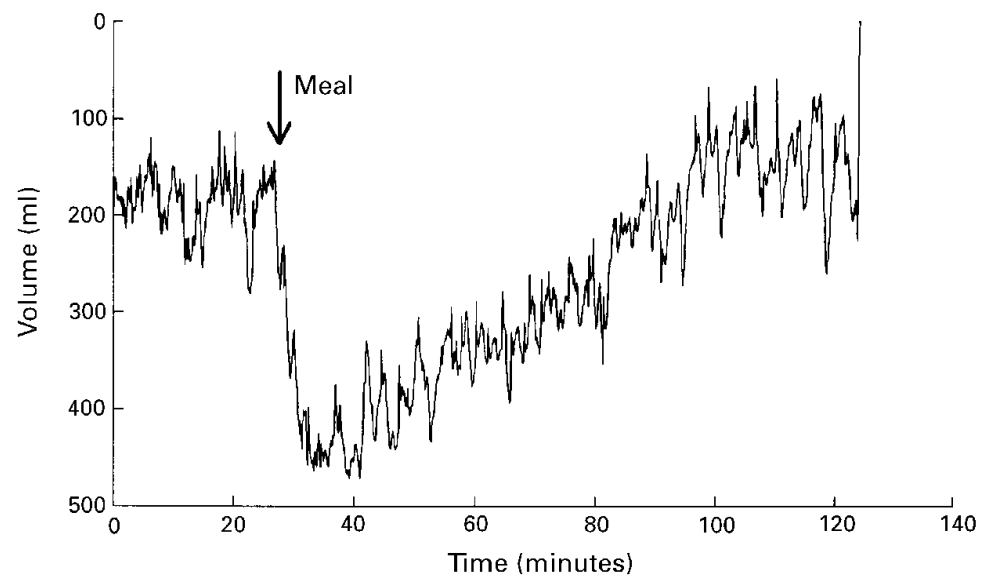

Figure 2 Example of a postprandial relaxation curve in a healthy volunteer. Baseline volume was measured at minimal distending pressure $+1 \mathrm{~mm} \mathrm{Hg}$. After the meal there was an increase in gastric bag volume to a maximum. The volume returned to the baseline value within 80 minutes.
The volume display of the barostat is derived from the measurement of the length of the rubber bellows in the barostat pump. The display was adjusted after withdrawal of known volumes, at a constant pressure of $2 \mathrm{~mm} \mathrm{Hg}$, from the barostat with a large syringe. A second calibration step was needed, because the rubber bellows deforms in proportion to the pressure in the barostat. Keeping the external volume constant, the pressure was increased and the decrease in the displayed volume was measured. This step was repeated at different external volumes but constant total volume of gas. In rigid cylinder barostats, one would expect a volume decrease according to Boyle's law: $\mathrm{dV} / \mathrm{dP}=-\mathrm{V} / \mathrm{P}$, where $\mathrm{V}$ is the total gas volume and $\mathrm{P}$ the pressure. We found a value of $\mathrm{dV} / \mathrm{dP}=-5.76 \mathrm{ml} / \mathrm{mm} \mathrm{Hg}$, which is about four times too high. Instead of using Boyle's law with an unrealistic gas volume, we corrected all measurements by using the constant -5.76 $\mathrm{ml} / \mathrm{mm} \mathrm{Hg}$. All displayed volume changes can be thought of as a change due to pressure deviations from $2 \mathrm{~mm} \mathrm{Hg}$ and the real changes in external volume, and were corrected accordingly.

By measuring pressure in the gastric bag as well as in the barostat pump, we found that maintenance of a constant pressure is best achieved with a catheter with a large inner diameter. ${ }^{14}$ Therefore we used a wide singlelumen catheter to connect the bag to the barostat pump.

This set up avoids the spontaneous oscillations often encountered with double-lumen catheters and feedback control from the gastric bag. Double-lumen catheters have a narrower flow channel and a greater pressure gradient between the bag and the barostat pump. A phase difference between the gastric bag and the barostat pump results in the oscillations. When the pressure in the barostat pump is not known, the volume cannot be corrected. In the dynamic state, only averaged pressures in barostat and gastric bag are equal, and pressure gradients over a narrow catheter can be appreciable; we found up to $20 \mathrm{~mm} \mathrm{Hg}$ at high flow rates in a narrow catheter. Injection or aspiration of air was triggered when the pressure in the system differed from the preselected pressure by more than $0.2 \mathrm{~mm} \mathrm{Hg}$. A dynamic equilibrium establishes itself with equal mean pressures in the barostat and bag, and volumes can be calculated correctly from the volume and pressure in the barostat. The maximal rate of air flow was 2.4 litres per minute. The intragastric polyethylene bag (maximum volume $700 \mathrm{ml}$ ) was mounted on the tip of a single-lumen 14-F polyvinyl tube and connected to the barostat. Pressure and volume were recorded on a paper polygraph and stored in a computer. The barostat was used to assess the compliance of the proximal stomach in the fasting state and the response of the proximal stomach to a liquid meal.

\section{EXPERIMENTAL DESIGN}

The studies were performed after an overnight fast; patients had taken no medication for at least 48 hours. Participants were placed in a 


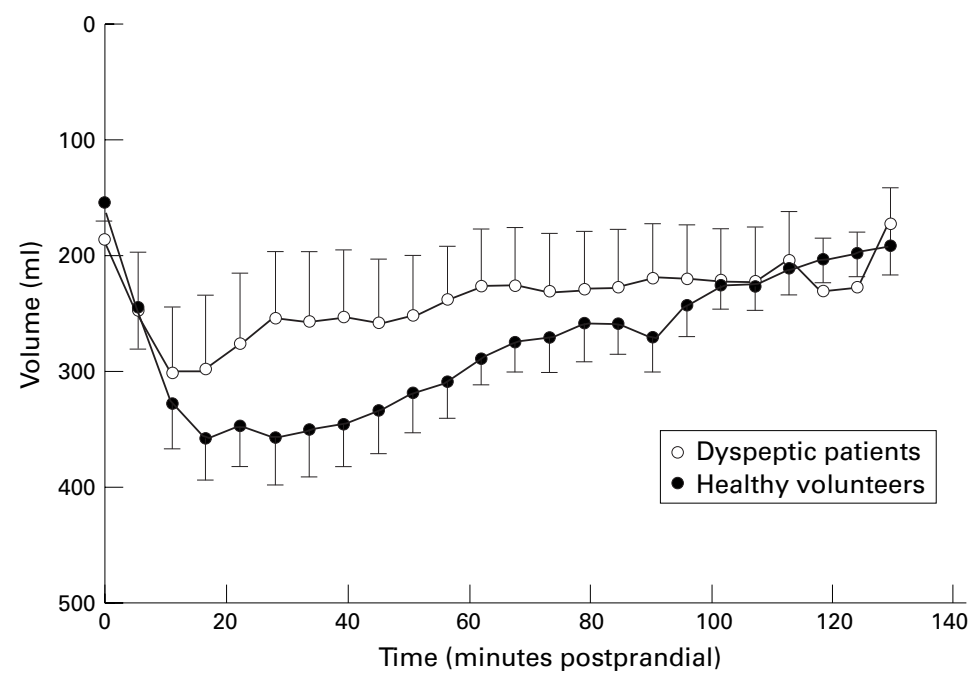

Figure 3 Mean postprandial relaxation curves in the dyspeptic patients and healthy volunteers. The increase in intragastric bag volume in the dyspeptic patients was significantly lower than that in the healthy volunteers $(p<0.05)$. The time interval between the start of ingestion of the meal and the time at which the maximum volume was reached was significantly shorter in patients than in controls $(p<0.01)$.

sitting position $\left(30^{\circ}\right.$ recumbent) and asked to relax comfortably. The lubricated bag, folded in a zigzag fashion, was introduced through the mouth into the proximal stomach. After the bag had been slowly inflated manually with 100 $\mathrm{ml}$ air to unfold it, it was completely deflated and, after a 10 minute interval, connected to the barostat.

Compliance measurement

First the minimal distending pressure (MDP) was determined as the lowest pressure level that provided a mean intrabag volume of 30 $\mathrm{ml}^{3}{ }^{15}$; at this pressure, respiratory induced volume changes could be distinguished. Starting at MDP, the pressure was increased stepwise every three minutes with $2 \mathrm{~mm} \mathrm{Hg}$ increments. At each level, both the intragastric volume and the perception of symptoms elicited by gastric distension were recorded. The pressure was increased until the volume exceeded $650 \mathrm{ml}$, or when the subject indicated that no further distension could be tolerated. Then the pressure was decreased stepwise with $2 \mathrm{~mm} \mathrm{Hg}$ steps, and intragastric volume only was measured.
Accommodation to a meal

After measurement of the compliance of the proximal stomach, intraballoon pressure was kept at atmospheric pressure $(0 \mathrm{~mm} \mathrm{Hg})$ for a period of 10 minutes. Thereafter, a period of 45 minutes followed during which MDP +1 $\mathrm{mm} \mathrm{Hg}$ was maintained before the participants ingested the liquid meal. The subjects were asked to drink the meal at a rate of $200 \mathrm{ml} / \mathrm{min}$. At a constant intragastric pressure of $1 \mathrm{~mm} \mathrm{Hg}$ above the MDP, volume changes were recorded over 1.5 hours.

\section{Assessment of gastrointestinal symptoms}

During the compliance measurement, perception of gastric distension was scored just before the next increase in pressure, by using a visual analogue scale from 0 to 10 (0, absence of sensation; 10, unbearable sensation). The participants were informed about the possible sensations: nausea, bloating, and pain. Postprandially the sensations of nausea, bloating, and pain were scored every 10 minutes.

\section{Meal}

The meal, which had a volume of $200 \mathrm{ml}$, was composed of $34 \mathrm{~g}$ Nutrilose (a lactose free milk powder; Nutricia, Zoetermeer, The Netherlands), $14 \mathrm{~g}$ Fantomalt (dextrin-maltose; Nutricia), and water. Energy content was $200 \mathrm{kcal}$ $(1.0 \mathrm{kcal} / \mathrm{ml})$; it was gluten- and lactose-free, with $9.8 \mathrm{~g}$ protein, $4.5 \mathrm{~g}$ fat, and $30.7 \mathrm{~g}$ carbohydrate.

\section{DATA ANALYSIS}

To construct the compliance curve, the average volume during the last minute of every three minute period was taken as intrabag volume at that pressure level. The compliance was taken as the regression coefficient of the steep part of the ascending branch of the volume-pressure curve. The difference between the rising and descending volume-pressure curve ("hysteresis") was measured by subtracting the volume of the ascending curve from the descending curve at $0,2,4,6$, and $8 \mathrm{~mm} \mathrm{Hg}$ above the MDP. The preprandial intragastric volume was measured, at a preselected level of MDP + 1 $\mathrm{mm} \mathrm{Hg}$, by averaging the volume over a 10
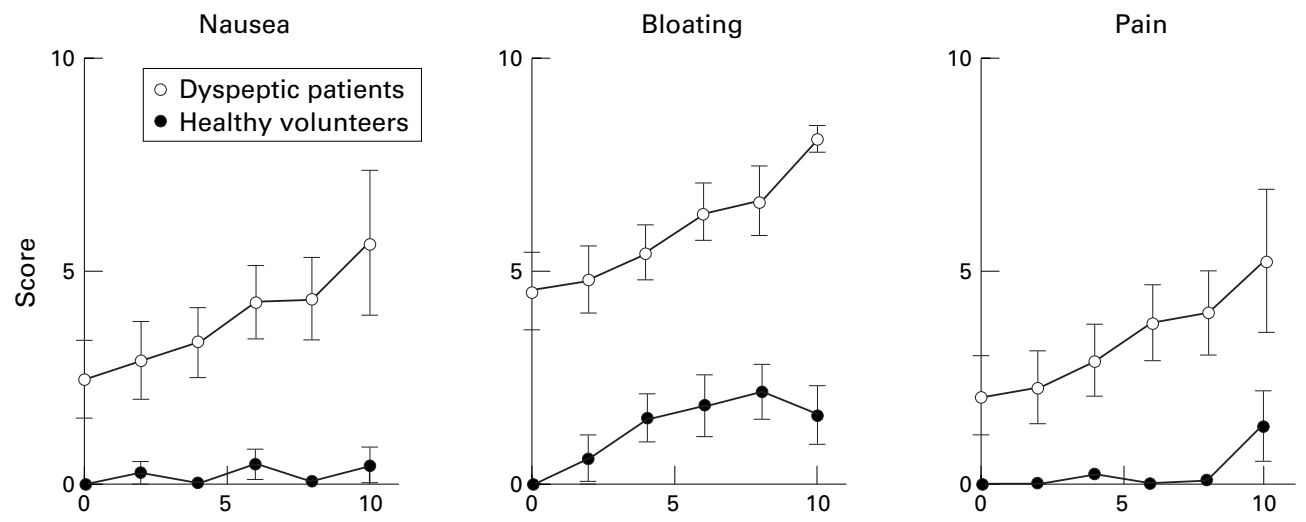

Pressure above MDP $(\mathrm{mm} \mathrm{Hg})$

Figure 4 Nausea, bloating, and pain scores in relation to the gastric bag pressure above the minimal distending pressure $(M D P)$ in dyspeptic patients and healthy volunteers. There was a significantly greater increase in nausea and pain scores with increasing pressure in the patients than in the healthy volunteers $(p<0.05, p<0.01)$. 

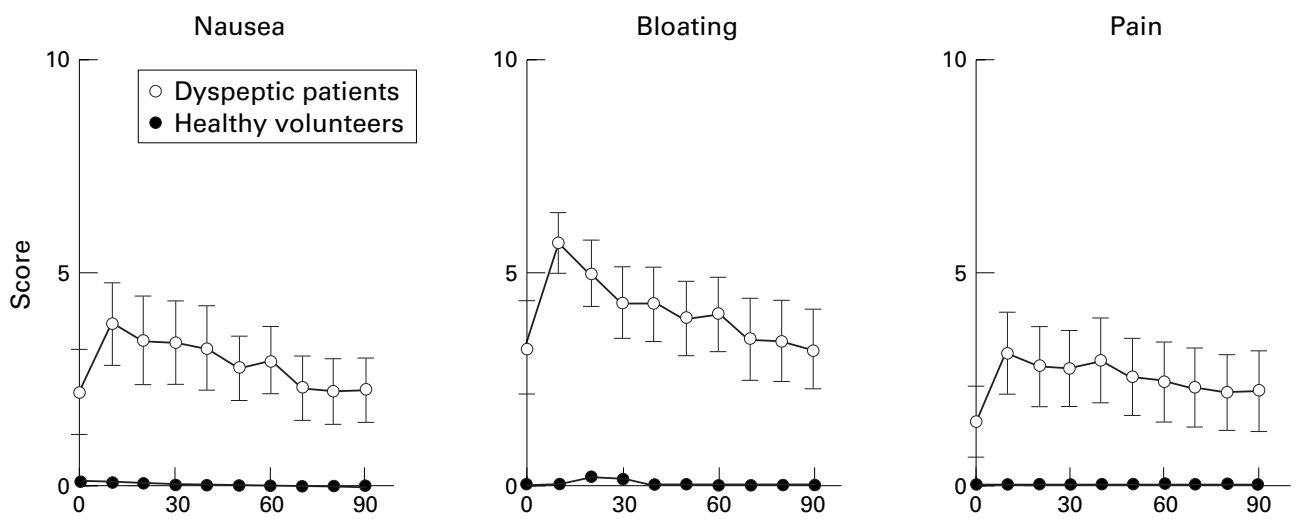

Time (minutes postprandial)

Figure 5 Nausea, bloating, and pain scores after the test meal in dyspeptic patients and healthy volunteers. After the meal, the dyspeptic patients had significantly more nausea, bloating, and pain than the healthy volunteers $(p<0.05, p<0.05$, $p<0.05$ respectively). The patients showed a significant increase in bloating and pain scores $(p<0.05, p<0.04)$.

minute period. The response to a liquid meal was measured by averaging the intragastric bag volumes every four minutes and subtracting the averaged preprandial volume. The volume increase of the individual postprandial curves was expressed as the sum of these differences: the area above the curve (AAC).

The maximal relaxation volume $\left(\Delta \mathrm{V}_{\max }\right)$ and the time $\left(\mathrm{t}_{\max }\right)$ at which $\Delta \mathrm{V}_{\max }$ occurred were also determined.

The sensations, nausea, bloating, and pain, in relation to pressure levels and to the intragastric volumes (by grouping the volumes into $100 \mathrm{ml}$ classes) were recorded.

\section{STATISTICAL ANALYSIS}

Statistical analysis of the differences between the functional dyspepsia patients and the controls was performed by analysis of variance. The Mann-Whitney $U$ test was used to test the differences between patients and healthy volunteers for the hysteresis variable and the postprandial volume increase (AAC). p $<0.05$ was considered significant. Values are given as mean (SEM).

\section{Results}

COMPLIANCE MEASUREMENT

All healthy volunteers and dyspepsia patients completed the study. MDPs were similar in the dyspeptic patients and the controls (6.45 (0.5) and 6.5 (0.4) $\mathrm{mm} \mathrm{Hg}$ respectively). As shown in fig 1 , the pressure-volume curve in response to the stepwise pressure increase showed a larger volume at each pressure in the dyspeptic patients, resulting in a significant difference between the pressure-volume curves $(\mathrm{p}<0.05)$. The inflation curve showed a significantly steeper slope in the dyspeptic patients than in the controls (regression coefficient 53 (2.0) $v$ 46 (3) $\mathrm{ml} / \mathrm{mm} \mathrm{Hg} ; \mathrm{p}<0.05$ ), indicating a higher compliance of the proximal stomach in the dyspeptic patients.

The volumes during stepwise deflation of the intragastric bag remained higher than the volumes during inflation in both the patients $(\mathrm{p}<0.001)$ and the healthy volunteers $(p<0.001)$. At MDP, the deflation curve also ended on a higher volume than the starting volume of the inflation (for the patients 35 (3) and 161 (41) $\mathrm{ml}$ for the start and end respectively, and for the controls 26 (4) and 171 (35) $\mathrm{ml}$ respectively). The mean volume differences between the ascending and descending parts of the curves in the dyspeptic patients $(133 \mathrm{ml})$ and healthy volunteers $(150$ $\mathrm{ml})$ were not significantly different $(\mathrm{p} \approx 0.46)$.

ACCOMMODATION TO MEAL

As shown in fig 2, the response to the meal began with an immediate rise in the volume in the intragastric bag (gastric relaxation). Figure

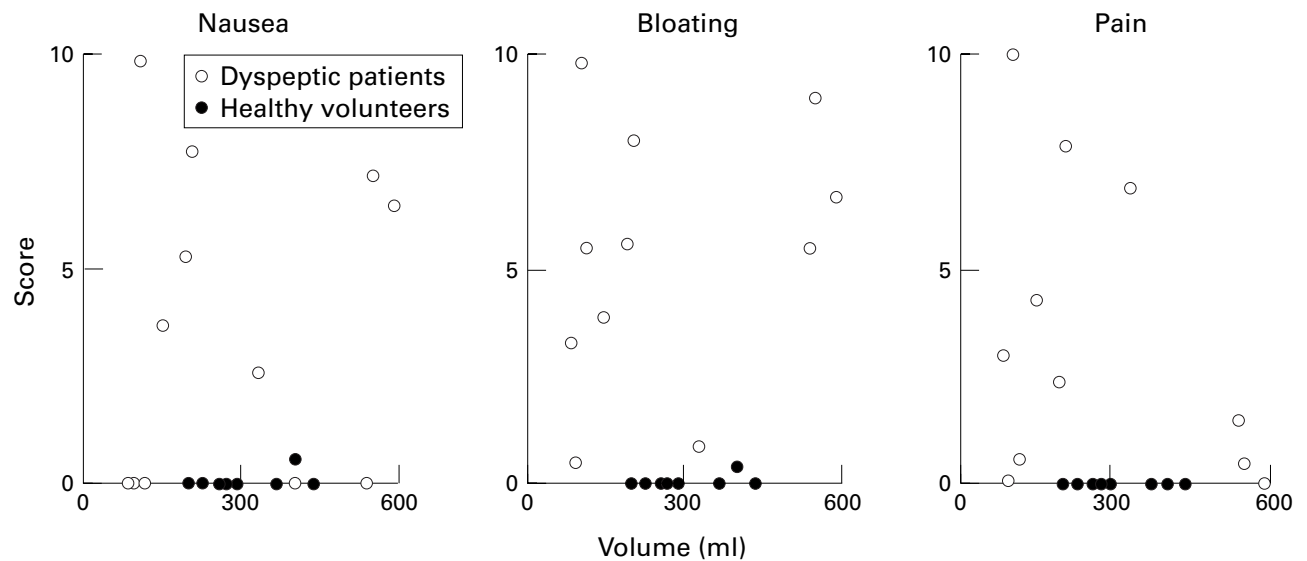

Figure 6 Individual nausea, bloating, and pain scores 10 minutes after the test meal plotted against relaxation volume. Postprandial symptoms are not related to volume. 
3 shows the mean increase in intragastric bag volume in the dyspeptic patients and healthy volunteers. The immediate rise in each group appeared to be the same; however, the controls continued to relax for a slightly longer period, thus reaching the maximum relaxation at a later time $\left(\mathrm{t}_{\max } 17\right.$ (2) $v 12$ (3) $\left.\min ; \mathrm{p}<0.01\right)$. However, the mean relaxation volumes were not significantly greater at any specific time ( $\mathrm{p}$ $\approx 0.18$ ), because of the large standard error of the mean. Because the relaxation in the volunteers remained slightly greater during the whole postprandial period, the time integrated relaxation was greater than in the patients (AAC 186 (26) v 83 (49) ml.h; p<0.05).

\section{SYMPTOMS}

The selected patients had a mean total symptom score of 11 (maximum symptom score 20). After intubation and before MDP was recorded, five patients reported nausea, nine had bloating, four experienced pain, and only three had no symptoms. None of the healthy volunteers were symptomatic after intubation and before recording of MDP.

During the study, dyspeptic patients experienced more symptoms than the controls (fig 4). In patients, the symptom scores correlated positively with intrabag pressure (nausea: $r=$ 0.98, p<0.01; bloating: $r=0.98, \mathrm{p}<0.01$; pain: $r=0.98, \mathrm{p}<0.01)$. In healthy controls, only bloating correlated positively with pressure $(r=$ $0.98, \mathrm{p}<0.01)$; the scores for nausea and pain remained low. Similar figures were found when scores were plotted against volume; however, with lower significance because of the higher variation in volumes (for patients: nausea $r=$ 0.74 , not significant; bloating $r=0.86, \mathrm{p}<0.05$; pain $r=0.82, \mathrm{p}<0.05$; for healthy controls: bloating $r=0.88, \mathrm{p}<0.05)$.

After the meal, dyspeptic patients had significantly more nausea, bloating, and pain than healthy volunteers $(p<0.05, p<0.05$, $\mathrm{p}<0.05$ respectively) (fig 5 ). After correction for preprandial scores, the increase in bloating and pain scores for the patients was still significant $(p<0.05, p<0.05)$. This was not seen for the nausea score $(p \approx 0.35)$. The symptoms increased during and after the liquid meal and gradually diminished during the following 80 minutes. No correlation between the symptom scores and the extent of gastric relaxation was found (fig 6).

\section{Discussion}

Dyspeptic patients can only tolerate smaller volumes than controls. A long standing point of debate is whether this is caused by mechanical inability to accommodate larger volumes or by hypersensitivity of the stomach wall. This study shows that at least the compliance of the stomach and the accommodation to volume are not impaired in our group of patients with non-ulcer dyspepsia. Applying progressively higher pressures to the intragastric bag resulted in a slightly greater volume increase at each pressure step than in controls. In other studies, the compliance of the proximal stomach in such patients was not significantly different. ${ }^{10-12}$ Holtmann et $a l^{16}$ concluded that the mode of distension can be of importance for the outcome of the compliance measurement of the proximal stomach. Lémann and coworkers $^{10}$ delivered increasing volumes at seven minute intervals, and in between completely deflated the elastic latex balloon for two minutes. They found a higher, although not significant, compliance in patients. Troncon et $a l^{11}$ also did not use a barostat. They applied stepwise $30 \mathrm{ml}$ volume distensions at one minute intervals and measured the resulting balloon pressure. Even though these studies evaluated compliance from pressure measurements at constant volume, whereas the barostat measures volumes at constant pressure, the results are not contradictory.

In addition to the effect of gradual distension of the proximal stomach, we studied the gradual return to baseline pressure. This was carried out by decreasing the pressure in steps of $2 \mathrm{~mm} \mathrm{Hg}$. In both patients and controls, the deflation curve showed higher volumes at every pressure level. The observed hysteresis phenomenon could be due to passive properties of the gastric wall, ${ }^{17}$ but also to active smooth muscle relaxation and contraction. The hysteresis was the same in patients and healthy volunteers. This implies that the proximal stomach, when looked upon as a distensible bag, has not only elastic but also viscous (relaxation) properties. Time of adaptation to a new pressure step is probably an important determinant of the final volume reached. The response to a pressure step consists of a relatively fast (less than a minute) adaptation, followed by a very slow increase. The hysteresis we found suggests that three minutes is not enough adaptation time to reach final equilibrium. The "true" compliance curve for long adaptation may be somewhere between the ascending and descending branches. That would also explain the baseline volume at $\mathrm{MDP}+1 \mathrm{~mm} \mathrm{Hg}$, after 45 minutes adaptation time before we gave the meal. The preprandial volumes found were between values read from the ascending and descending branch of the compliance curves.

The slightly higher compliance in the dyspeptic patients seen in this study may be the result of lower activity of vagal excitatory cholinergic fibres or higher activity of vagal inhibitory non-adrenergic non-cholinergic fibres. It is also possible, however, that inhibitory reflexes mediated by sympathetic pathways are altered.

Gastric tone is due to sustained muscular contraction of the gastric wall. The contraction of the proximal stomach determines the balance between gastric accommodation and gastric emptying. ${ }^{18}$ This study shows a different mechanism for relaxation upon mechanical distension, which was sightly greater in patients, and postprandial relaxation, which was lower in patients. Lower postprandial relaxation of the fundus may result in a different fundal-antral distribution in the stomach and a change in emptying rate. In a barostat study on six patients who had consumed a liquid meal, Ropert et $a l^{14}$ also found altered postprandial relaxation. In four of these patients, the 
emptying rate after a solid meal, measured on another day, was normal. The response to the liquid meal during the barostat study was particularly disturbed in these patients. The contribution of gastric emptying to postprandial symptoms in dyspeptic patients remains obscure, and can only be clarified by performing simultaneous barostat and emptying studies. Technical and radiation safety problems prevented us from doing so.

Mearin et $a l^{12}$ included patients with relatively mild symptoms, with a total symptom score of more than 6 out of a maximum of 15 . In their study, the patients were asymptomatic after an overnight fast and asymptomatic after intubation on the minimal distending level. We selected a group of severely dyspeptic patients with predominantly dysmotility-like symptoms. ${ }^{18}$ Our patient selection only included those with at least two gastrointestinal symptoms out of a five symptom complex (mean symptom score was 11 out of a maximum of 20). Most of our patients were experiencing symptoms after intubation and before recording of MDP, indicating that not only the distension but also even small intragastric "objects" such as the deflated bag caused discomfort.

Infusion of fluid nutrients into the stomach or duodenum causes a relaxation of the fundus, which is not due to the volume of the meal. ${ }^{17}$ The test meal of $200 \mathrm{kcal}$ in $200 \mathrm{ml}$ is sufficient to invoke a response and is well tolerated by all patients. The barostat pressure was kept at a constant low level, which has been shown not to influence the normal physiological pattern of motility in the postprandial period. ${ }^{13}{ }^{19}$ Postprandially the fundic volume increased until 12 (3) minutes in the patients and until 17 (2) minutes in the healthy volunteers. The return of the intragastric bag volume towards its basal value was more rapid in the dyspeptic patients than in the volunteers. These results suggest that, in patients with functional dyspepsia, the immediate relaxation is normal but the slow sustained adaptive relaxation is impaired. The faster return to baseline may reflect a faster emptying of the fundus. Altered duodenogastric reflexes is a plausible explanation for these results. ${ }^{20}$ Hormonal and neural mechanisms, such as adrenergic stimulation and nonadrenergic non-cholinergic fibres contained in the vagus nerves participating in the gastric relaxatory response induced by intestinal nutrients, may play a role as these have been shown to be involved in the relaxation response. $^{21}$

Over and above their already greater discomfort, the dyspeptic patients exhibited a significantly greater increase in nausea $(p<0.05)$ and pain $(\mathrm{p}<0.01)$ scores with increasing pressure than did the healthy volunteers, who reported hardly any increase in these symptoms. This was not the case, however, for bloating $(\mathrm{p} \approx$ 0.8 ), as the healthy volunteers also showed a substantial increase in bloating score with increasing pressure. Notivol and coworkers ${ }^{22}$ reported, in a study of healthy volunteers, that epigastric symptoms in response to gastric distension were related to both the intragastric pressure and the intragastric volume. Their data suggest that stress in the stomach wall may be the determining factor for the discomfort suffered after distension. In our distension study, the healthy volunteers had hardly any symptoms other than bloating. In the patients, the symptoms increased with pressure and, to a lesser extent, also with volume. Volume tends to be more variable between individuals. ${ }^{23}$ Therefore the correlation with volume was not significant.

After the liquid meal, dyspeptic symptoms increased. In the patients, which were selected on the basis of gastrointestinal symptoms, the increases in bloating and pain scores were significant. The symptoms showed no correlation with relaxation volume. In contrast with the higher compliance in the fasted state, the mean postprandial relaxation volumes in patients were lower than in volunteers, making it doubtful that postprandial volume or global stress in the gastric wall is the main cause of their increased postprandial symptoms. However, we cannot exclude the possibility that regions of higher stress exist locally in the gastric wall, which could cause the higher visceral sensitivity. In conclusion, this study shows that the proximal stomach of patients with functional dyspepsia show slightly increased compliance to mechanical distension in the fasting period, but decreased postprandial relaxation. The extent of postprandial relaxation did not correlate with the symptoms. The results of this study confirm that, in patients with functional dyspepsia, visceral hypersensitivity of the stomach plays a major role in their symptoms.

This study was presented in the Plenary Poster Session at the American Gastroenterology Association held in San Diego, 1995 and appeared in abstract form in Gastroenterology 1995 and app

1 Talley NJ, Piper DW. The association between non-ulcer Talley NJ, Piper DW. The association between non-ulcer
dyspepsia and other gastrointestinal disorders. Scand $f$ dyspepsia and other gastroint
Gastroenterol 1985;20:896-900.

2 Wegener M, Börsch G, Schaffstein J, et al. Are dyspeptic symptoms in patients with campylobacter pylori-associated type B gastritis linked to delayed gastric emptying? $\mathrm{Am} \mathcal{f}$ Gastroenterol 1988;83:737-40.

3 Jian R, Ducrot F, Ruskone A, et al. Symptomatic, radionuclide and therapeutic assessment of chronic idiopathic dyspepsia. Dig Dis Sci 1989;34:657-64.

4 Stanghellini V, Ghidini C, Ricci Maccarini M, et al. Fasting and postprandial gastrointestinal motility in ulcer and nonulcer dyspepsia. Gut 1992;33:184-90.

5 Bassotti G, Pelli MA, Morelli A. Duodenojejunal motor activity in patients with chronic dyspeptic symptoms. F Clin Gastroenterol 1990;12:17-21.

6 Camilleri M, Brown ML, Malagelada J-R. Relationship between impaired gastric emptying and abnormal gastroin-

7 Malagelada JR, Stanghellini V. Manometric evaluation of Malagelada JR, Stanghellini V. Manometric evaluation of
functional upper gut symptoms. Gastroenterology 1985;88: 1223-31.

8 Malagelada JR. Gastrointestinal motor disturbances in functional dyspepsia. Scand F Gastroenterol 1991; suppl 182: 29-32.

9 Bradette M, Paré P. Visceral perception in health and in functional dyspepsia. A cross-over study of gastric distension with placebo and domperidone. Dig Dis Sci 1991;36: $52-8$.

10 Lémann M, Dederding JP, Flourié B, et al. Abnormal perception of visceral pain in response to gastric distension in chronic idiopathic dyspepsia, the irritable stomach syndrome. Dig Dis Sci 1991;36:1249-54.

11 Troncon LEA, Thompson DG, Ahluwalia NK, et al. Relations between upper abdominal symptoms and gastric pepsia and after vagotomy. Gut 1995;37:17-22.

12 Mearin F, Cucala M, Azpiroz F, et al. The origin of Mearin F, Cucala $M$, Azpiroz F, et al. The origin of
symptoms on the brain-gut axis in functional dyspepsia. Gastroenterology 1991;101:999-1006.

13 Azpiroz F, Malagelada JR. Physiological variations in canine gastric tone measured by an electronic barostat. Am $\mathcal{F}$
Physiol 1985;248:G229-37. 
14 Ropert A, Bruley Des Variannes S, et al. Simultaneous assessment of liquid emptying and proximal gastric tone in .

15 Azpiroz F, Malagelada JR. Gastric tone measured by an electronic barostat in health and postsurgical gastroparesis. Gastroenterology 1987;92:934-43

16 Holtmann G, Guerra G, Gschossemann J, et al. Measurement of gastric sensory function and compliance: effects of the distension mode. Gut 1995;37:A102

17 Ahluwalia NK,Thompson DG, Barlow J, et al. Relaxation responses of the human proximal stomach to distension during fasting and after food. Am f Physiol 1994;267: G166-72.

18 Colin-Jones DG, Bloom B, Bodemar G, et al. Management of dyspepsia: report of a working party. Lancet 1988;1:576-9.
19 Azpiroz F, Malagelada JR. Pressure activity patterns in the canine proximal stomach: response to distension. $A m \mathcal{F}$ canine proximal stomach:
Physiol 1984;247: G265-72.

20 Azpiroz F, Malagelada JR. Intestinal control of gastric tone. Am F Physiol 1985;249:G501-9.

21 Azpiroz F, Malagelada JR. Importance of vagal input in maintaining gastric tone in the dog. F Physiol (Lond) 1987; 384:511-24.

22 Notivol R, Coffin B, Azpiroz F, et al. Gastric tone determines the sensitivity of the stomach to distension. Gastroenterology 1995;108:330-6.

23 Whitehead WE, Delvaux M. Standardization of barostat procedures for testing smooth muscle tone and sensory thresholds in the gastrointestinal tract. Dig Dis Sci 1997;42: 223-41.

\section{Erratum}

The incorrect abstract was printed as TF294 in the 1998 BSG abstract book (Gut 1998;42:(suppl 1):A74. The correct abstract is reproduced below.

\section{DIFFERENT EFFECTS OF $\operatorname{cag} A^{+} /$vacA [s1a/m1] $H$. PYLORI ON RAT} GASTRIC MUCOSAL MICROCIRCULATION IN VIVO

Kalia N, Reed MWR, Morton $\mathrm{D}^{\circ}$, Atherton $\mathrm{JC}^{\dagger}$, Jacob S', Bardhan $\mathrm{KD}^{\circ}$; Brown NJ; Departments of Surgical and Anaesthetic Sciences \& 'Biomedical Science, University of Sheffield; 'District General Hospital, Rotherham; ' University Hospital, Nottingham

Background: We have previously demonstrated that pooled extracts of $H$. pylori from duodenal ulcer/gastritis patients induce platelet aggregation but not leukocyte activation within rat gastric mucosal microcirculation (GMMC) in vivo [Gut 97;41:748-52]. However, the more pathogenic strains may exert greater effects on the microcirculation.

Aims: To determine the acute effects of two pure extracts of $\operatorname{cag} A^{+} / v a c A[\mathrm{~s} 1 \mathrm{a} / \mathrm{m} 1]$ strains, from two patients, on rat GMMC in vivo. Specifically, macromolecular leakage of labelled albumin, platelet and leukocyte activation and vessel diameters were assessed.

Methods: An incision made in the exteriorised stomach of anaesthetised rats (hypnorm:diazepam $1: 1$ ratio; $0.1 \mathrm{mg} / 100 \mathrm{~g}$ ) allowed visualisation of the mucosal surface. $0.5 \mathrm{mls}$ of an aqueous extract from strain $60190(n=12)$ or J104 $(n=10)$ was administered topically. Acridine red $(0.1 \mathrm{ml} / 100 \mathrm{~g}$; i.a) was used to quantitate leukocyte and platelet activity. Fluoroscein-labelled albumin $(0.2 \mathrm{ml} / 100 \mathrm{~g}$; i.a) was used to quantitate macromolecular leakage $(\mathrm{MML})$ and alterations in capillary and post-capillary venule (PCV) diameters. Observations were made every 15 mins for 2 hrs using fluorescent in vivo microscopy.

Results: Strain 60190 induced significant sustained increases in MML, by 5 mins $(41 \% ; p<0.01)$. Less leakage was observed with $\mathrm{J} 104$ which was transient, reaching significance at 60 mins only $(18 \%$; $p<0.05)$. 60190 induced rapid leukocyte adhesion within 5 mins $(8.60 \pm 2.67$; $p<0.05)$ with significant rolling leukocytes at 45 mins $(2.90 \pm 1.28$; $\mathrm{p}<0.05 ;)$. J104 induced significant leukocyte adhesion after 45 mins $(11.65 \pm 3.60 ; p<0.05 ;)$. Platelet emboli were only observed with 60190 treated animals at 60 mins $(2.30 \pm 0.99 ; p<0.05)$. PCV vasoconstriction was observed only at 5 mins with $60190(24.2 \mu \mathrm{m} \pm 1.62 \mu \mathrm{m}$ to $18.94 \mu \mathrm{m}$ $\pm 1.81 \mu \mathrm{m} ; \mathrm{p}<0.05)$. Values represent mean above baseline \pm S.E.M. Conclusions: Extracts of $H$. pylori strains possessing both $\operatorname{cag} A$ and the $\operatorname{vac} A[\mathrm{~s} 1 \mathrm{a} / \mathrm{m} 1]$ genotype are associated with marked disturbances within the GMMC. The data suggests that some $\operatorname{cag} A^{+} / v a c A[s 1 \mathrm{a} / \mathrm{m} 1]$ strains are more toxic and/or other genes may be involved.

Funded by Bardhan Research \& Education Trust; Registered charity: 328452 